\title{
CULTURA CORPORATIVA: DETERMINANTE OU LIMITANTE ESTRATÉGICO PARA O BRANDING
}

\author{
Corporate culture: determinant or strategic limitation for \\ Branding
}

\section{Cultura corporativa: determinante o limitante estratégico para el Branding}

\begin{abstract}
Martha Gabriel
Pontifícia Universidade Católica de São Paulo, São Paulo, Brasil

Professora do Programa de Pós-Graduação Tecnologias da Inteligência e Design Digital da Pontifícia Universidade Católica de São Paulo. Doutora em Artes pela Escola de Comunicações e Artes da Universidade de São Paulo. Email: martha@martha.com.br
\end{abstract}

\section{Clotilde Perez}

Universidade de São Paulo, São Paulo, Brasil.

Professora Titular de Publicidade e Consumo da Escola de Comunicações e Artes da Universidade de São Paulo. Doutora em Comunicação e Semiótica pela Pontifícia Universidade Católica de São Paulo. Líder do Grupo de Estudos Semióticos em Comunicação, Cultura e Consumo. Fundadora da Casa Semio.

Email: cloperez@terra.com.br

RESUMO Este artigo busca apresentar o conceito de cultura corporativa, bem como demonstrar sua essencialidade nas estratégias de branding. Por ser determinante do êxito do branding, a cultura corporativa pode favorecer os caminhos estratégicos, mas também pode inviabilizálos, necessitando, portanto, de intervenções e ajustes para sua exequibilidade. A metodologia aqui proposta é a dos "3Es", uma adaptação da metodologia de engajamento e transformação social: educação, estrutura e estímulo, centrando na educação os melhores esforços, como fundamento essencial da estrutura e do estímulo.

PALAVRAS-CHAVE Cultura corporativa, Branding, Engajamento.

ABSTRACT This article aims to present the concept of corporate culture, as well as to demonstrate its essentiality in branding strategies. As it is a determining factor of the success of branding, corporate culture can favor strategic paths, but it can also make them unfeasible, necessitating, therefore, interventions and adjustments for their feasibility. The methodology proposed here is the "3Es", an adaptation of the methodology of engagement and social transformation: education, structure and stimulus, focusing on education the best efforts, as the essential foundation of structure and stimulation.

KEYWORDS Corporate culture, Branding, Engagement.

RESUMEN Este artículo busca presentar el concepto de cultura corporativa, así como demostrar su esencialidad en las estrategias de branding. Por ser un determinante del éxito del branding, la cultura corporativa puede favorecer los caminos estratégicos, pero también puede inviabilizarlos, necesitándose, por lo tanto, de intervenciones y ajustes para su viabilidad. La metodología aquí propuesta es la de los “3Es”, una adaptación de la metodología de compromiso y transformación social: educación, estructura y estímulo, centrándose en la educación los mejores esfuerzos, como fundamento esencial de la estructura y del estímulo.

PALABRAS CLAVE Cultura corporativa, Branding, Compromiso. 
Com a penetração e disseminação das tecnologias digitais no cotidiano das pessoas, temos experimentado uma sobrecarga informacional decorrente da popularização e fragmentação das plataformas de publicação e compartilhamento de conteúdos. As marcas hoje enfrentam concorrência não apenas de outras marcas com seus produtos, informações e significações, mas também, e principalmente, dos conteúdos postados pelos próprios consumidores, seus amigos e famílias, clubes, grupos de estudo, escolas, blogs, mídias sociais etc. O excesso de informação nos causa precariedade de atenção - esse fenômeno, muito estudado em diversas regionalidades científicas, intensifica-se e torna-se foco de estudo nas áreas da comunicação e marketing com o título de Economia da Atenção (DAVENPORT; BECK, 2001). Nesse sentido, estamos diante do fato de que a coisa mais valiosa hoje seja a atenção do consumidor/cliente (e não mais apenas a audiência) e, para conquistá-la, é preciso ser mais relevante e atrativo do que "todo o resto junto". Dessa forma, relevância tem se tornado um "mantra" em todos os ambientes - da vida pessoal ao mundo dos negócios, pois ela funciona como um imã de atenção.

Nesse contexto, um dos maiores desafios para as marcas passa a ser a conquista da atenção dos seus públicos para engajá-los (linguagem do marketing) ou para construir vínculos de sentidos (linguagem semiótica e comunicacional). Engajar é envolver, é trazer o outro para o mesmo caminho que estou e, no caso, para o universo sígnico da marca (PEREZ, 2016). Para que isso aconteça, é necessário primeiramente que consigamos chamar a sua atenção para despertar nele o envolvimento e a ação que desejamos.

Vários fatores podem contribuir para o engajamento dos diversos públicos de uma organização (tanto externos quanto internos), como estratégias de conteúdo, storytelling, branded content, advertisement e branding. No entanto, o pilar fundamental para garantir diferenciação e dotar os produtos de significado para alcançar relevância é o branding, que deve estar em todas as demais estratégias de engajamento, pois sem ele, conteúdo e storytelling perdem o sentido e sua força estratégica para a organização. Por meio do branding, conseguimos orquestrar e fortalecer a voz corporativa em todas as suas dimensões para que a marca e seus valores ecoem de forma consistente e coerente sem causar dissonâncias e diminuindo a dispersão.

No entanto, para que o branding consiga funcionar para o público externo, é necessário que ele funcione, antes de mais nada, para o público interno, caso contrário, não se consegue um fluxo estratégico coerente e sustentável para engajar verdadeiramente as pessoas. Da mesma forma que um ser humano não consegue agir adequadamente no mundo quando algum dos seus órgãos internos tem problemas, uma organização tem sua performance prejudicada quando as suas partes internas não estão alinhadas com as estratégias externas. Por menor que seja a disfunção interna, ela pode afetar de forma significativa o funcionamento do corpo como um todo. Por exemplo, se alguém estiver com uma simples dor de cabeça, provavelmente não conseguirá trabalhar ou se divertir como deveria. Uma unha lascada ou encravada desvia nossa atenção e atuação no mundo, prejudicando nossos pensamentos e atividades, portanto, para conseguirmos engajamento dos públicos externos por meio do branding, precisamos conquistar engajamento dos públicos internos, que são fortemente influenciados pela cultura corporativa, como veremos a seguir. 


\section{CULTURA: COMPREENSÃO E DEFINIÇÕES}

Cultura é um conceito extremamente complexo e impossível de ser definido de forma única sem caminhar para a redução. No entanto, Geertz (1989) apresenta um conceito muito rentável às nossas reflexões: "a cultura é uma teia de significados tecida pelo homem. Essa teia orienta a existência humana. Trata-se de um sistema de símbolos que interage com os sistemas de símbolos de cada indivíduo numa interação recíproca”. Tal definição, mais semiótica do que antropológica, oferece a nós a riqueza "da teia de significados", que traz a complexidade e a cotidianidade como princípios fundadores da cultura. Também traz a perspectiva da construção: não está pronta, mas vai sendo construída e consolidada com o tempo. No contexto deste trabalho, cultura refere-se ao "modo de vida" de um grupo particular de pessoas, seus costumes, língua e crenças gerais, em uma determinada época e seus significados. Em outras palavras, a cultura é aquilo que nos une em nossas crenças, em nossos costumes e modos de fazer as coisas, em nossos valores sociais, que se manifestam em tramas de significações sempre em crescimento, princípio peirceano fundamental (PEIRCE, 1977). Como nos apresenta Santaella (2003, p. 29-30), cultura é mistura, referindose ao amálgama caraterístico da chamada cultura contemporânea. Também faz menção ao livro Culturas híbridas de Canclini (1990) como referência aos estudos sociológicos da cultura nos dias atuais. Mas a chamada breve definição útil de cultura é realmente definitiva "cultura é a parte do ambiente que é feita pelo homem (SANTAELLA, 2003, p. 31).

De modo sintético, podemos entender que enquanto a genética é propagada por meio de hereditariedade, a cultura é transmitida pela aprendizagem. Um comportamento de grupo que se repete em qualquer lugar do planeta é biológico; se não se repete, é aprendido e, portanto, cultural. A cultura funciona como um filtro pré-estabelecido para o que desejamos ou rejeitamos, o que acreditamos ou desconfiamos, o que vemos ou deixarmos de ver, atuando como uma lente pela qual enxergamos o mundo e tentamos entendê-lo para agir. A cultura influencia nossas percepções, uma vez que a percepção está limitada a tudo que nós estamos preparados para perceber (SANTAELLA, 2011). Nossas lentes culturais são únicas, pois são construídas por meio das nossas experiências individuais ou coletivas ao longo da vida, nossas redes de significados. Diferentes interpretações de mundo geram diferentes sentimentos e comportamentos nos indivíduos, portanto, culturas distintas possuem modos diferentes de pensar, atuar e se emocionar. Como exemplo, a Figura 1 mostra a diferença das cores associadas a cada sentimento em diversas culturas culturas distintas geram sentimentos distintos para a mesma cor.

Ainda que tenhamos realizado um breve percurso sobre os sentidos da cultura, o que nos interessa nesta reflexão é a cultura organizacional e, nesse aspecto, podemos concluir que:

a) A cultura é um forte determinante de como pensamos, percebemos, nos comportamos e agimos.

b) Por ser aprendida, e não uma característica biológica herdada, a cultura pode ser reaprendida e modificada.

c) O princípio semiótico da cultura impõe seu crescimento constante.

\section{A importância estratégica da cultura corporativa}

Quando pensamos em qualquer tipo de estratégia, temos como objetivo alcançar algum resultado desejado. Considerando-se que a 
cultura influencia profundamente nossos comportamentos e ações, sendo que estes, por sua vez, determinam os nossos resultados, podemos dizer que a cultura tem um papel importante no resultado que alcançamos ou deixamos de alcançar. Culturas que valorizam prioritariamente a educação, por exemplo, obtêm resultados distintos de culturas que valorizam mais os esportes ou a estética. Culturas que priorizam a sustentabilidade ou a felicidade geram ações e soluções diferentes das culturas que valorizam mais o resultado financeiro.

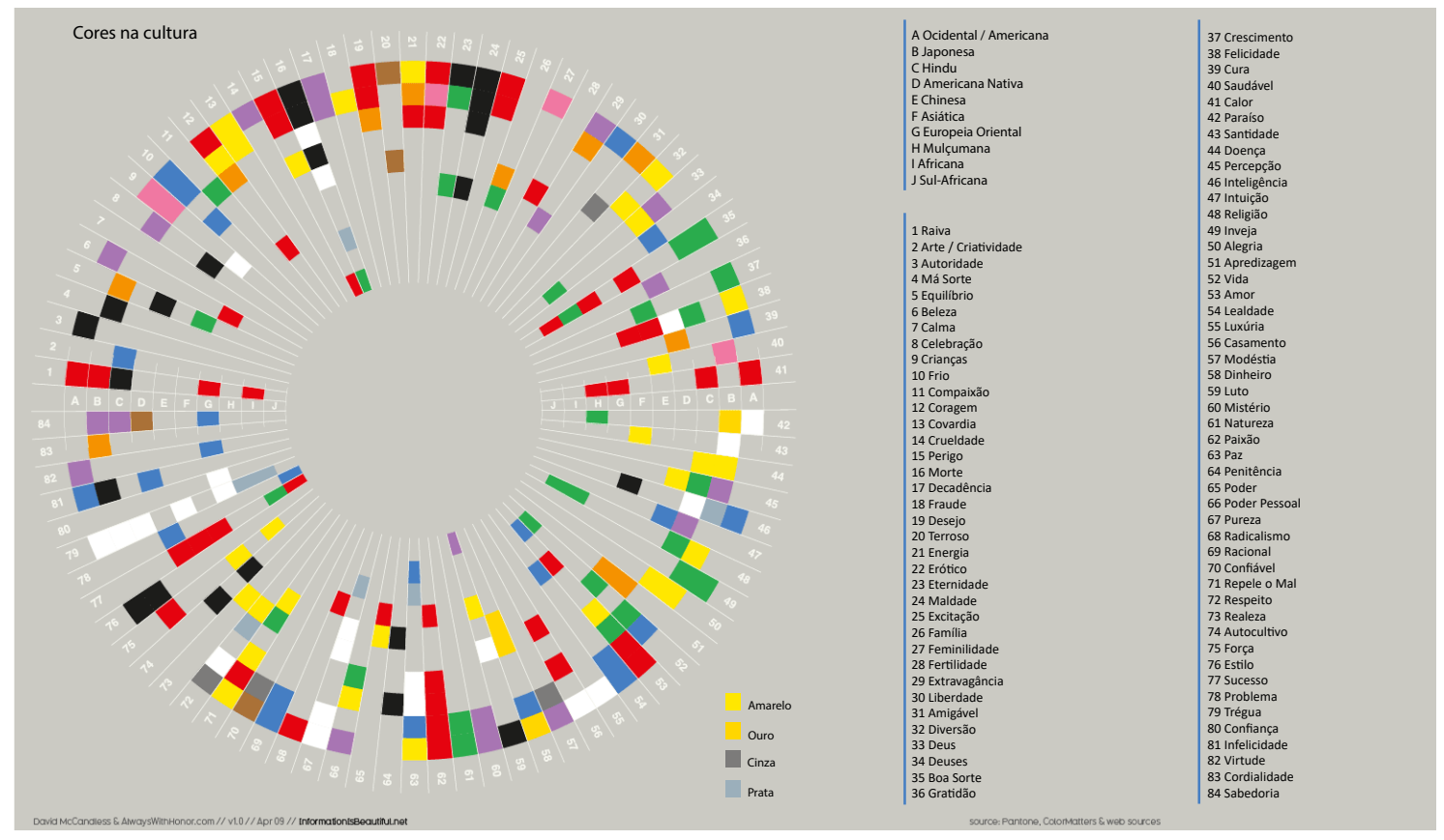

Figura 1. Mapa do significado das cores em diversas culturas.

Fonte: Colors (2016)

Quando uma ação estratégica é proposta em um grupo de pessoas, ela tem pouca ou nenhuma chance de se realizar se não for ressonante com a cultura desse grupo: se as pessoas não acreditam que algo é importante, não existe motivação para fazê-lo, ou pior, se acreditam que algo é errado ou desnecessário, provavelmente irão combatê-lo. Por outro lado, se a estratégia abraçar e enredar os valores da cultura, ela funciona como um catalisador para o processo, impulsionando-o. Edgard Schain, professor de psicologia do Massachusetts Institute of Technology (MIT), ilustra esse comportamento por meio da frase "A cultura determina e limita a estratégia" (SCHAIN, 2009). Peter Drucker, considerado o pai da administração moderna, frequentemente argumentava que a cultura de uma organização venceria qualquer tentativa de se criar uma estratégia que fosse incompatível com ela. Em outras palavras, a cultura sempre vence a estratégia - seja em gestão, marketing, branding, inovação etc. Não se consegue resultados quando trabalhamos contra a cultura. Consequentemente, a cultura é um fator essencial para qualquer tipo de resultado, o que a torna estrategicamente importante. A Figura 2 ilustra 0 alinhamento necessário entre cultura e estratégia para se alcançar resultados.

\section{Branding e cultura corporativa}

Vimos que a cultura determina valores, crenças, percepções e significados que se manifestam por meio da comunicação, dos comportamentos e atitudes das pessoas. Assim também acontece na cultura corporativa, ainda 
que dentro de um ambiente mais restrito e controlado - a organização. Por sua vez, considerando-se que o branding é uma disciplina estratégica que está intimamente ligada a valores, crenças, percepções e significados, que devem ser transmitidos por meio de comunicação e atuação (comportamento) das marcas, podemos argumentar que as estratégias de branding das organizações são profundamente dependentes da sua cultura corporativa. Um exemplo que ilustra essa relação entre branding e cultura corporativa é o caso da ação de comunicação d'O Boticário no dia dos namorados em 2015 (Figura 3), que foca na igualdade de gêneros: o filme destaca valores praticados na cultura interna da organização (e que fazem parte da sua governança corporativa) que, por sua vez, reforça 0 posicionamento e o branding estratégicos, favorecendo-os.

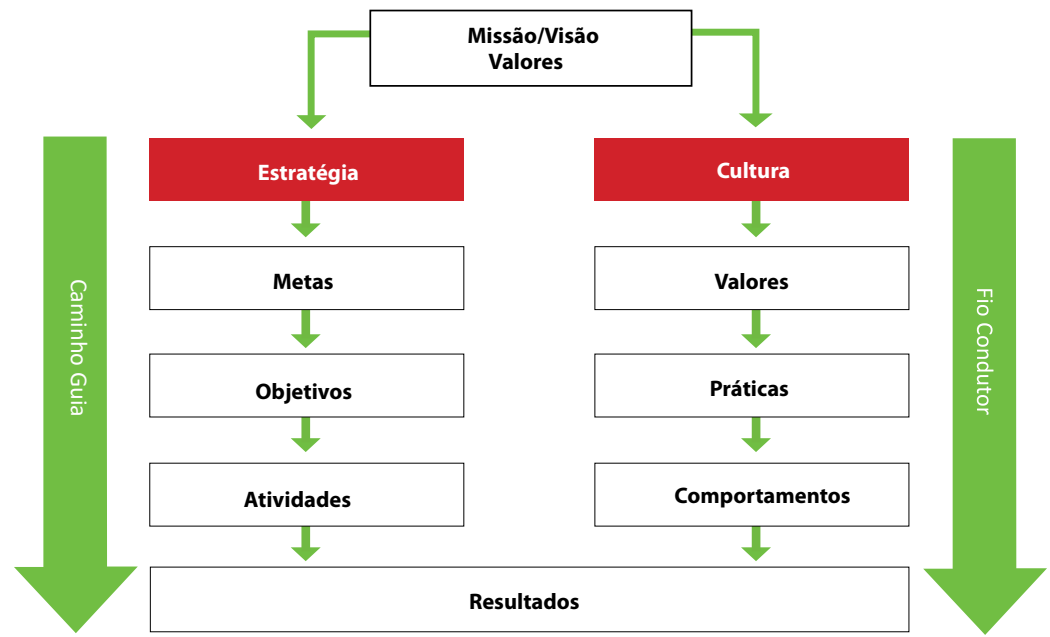

Figura 2. Alinhamento entre os elementos da estratégia e da cultura para alcançar resultados.

Fonte: Torben (2013).
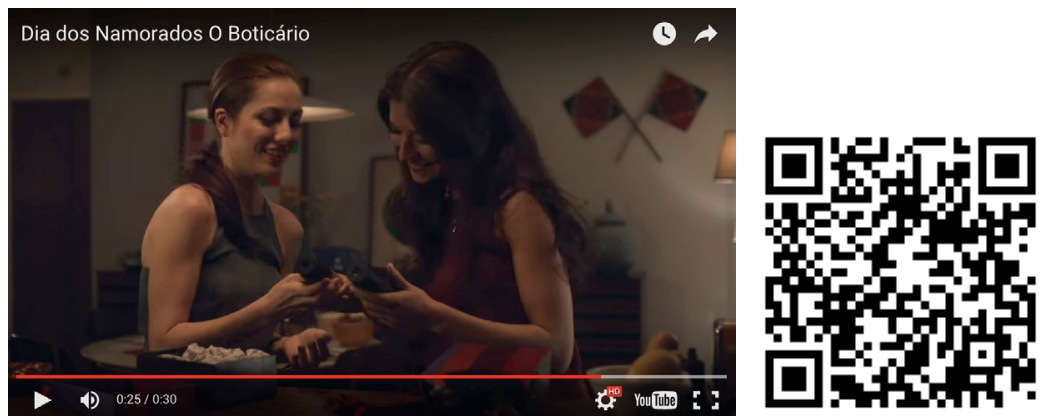

Figura 3. Campanha do dia dos namorados d’O Boticário em 2015. Fonte: Dia (2015).

No entanto, para usarmos a cultura corporativa a nosso favor e evitar que ela mine nossos esforços estratégicos, precisamos conhecer os elementos que formam essa cultura de modo a nos apropriarmos deles ou, eventualmente, transformá-los para alinhá-los com os objetivos de branding. Analisaremos a seguir esses elementos e os desafios que eles apresentam.

\section{Os elementos escondidos da cultura}

Toda cultura é composta por duas partes principais: primeiro, os elementos que conseguimos ver e detectar rapidamente - língua, tradições, 
alimentação, vestimenta etc. -; depois, os fatores invisíveis que não conseguimos perceber facilmente, mas que determinam a parte visível e a estruturam: crenças, valores, desejos, percepções, expectativas etc. Uma metáfora clássica que representa essa relação entre os elementos visíveis e invisíveis da cultura é o iceberg, conforme apresentado na Figura 4.

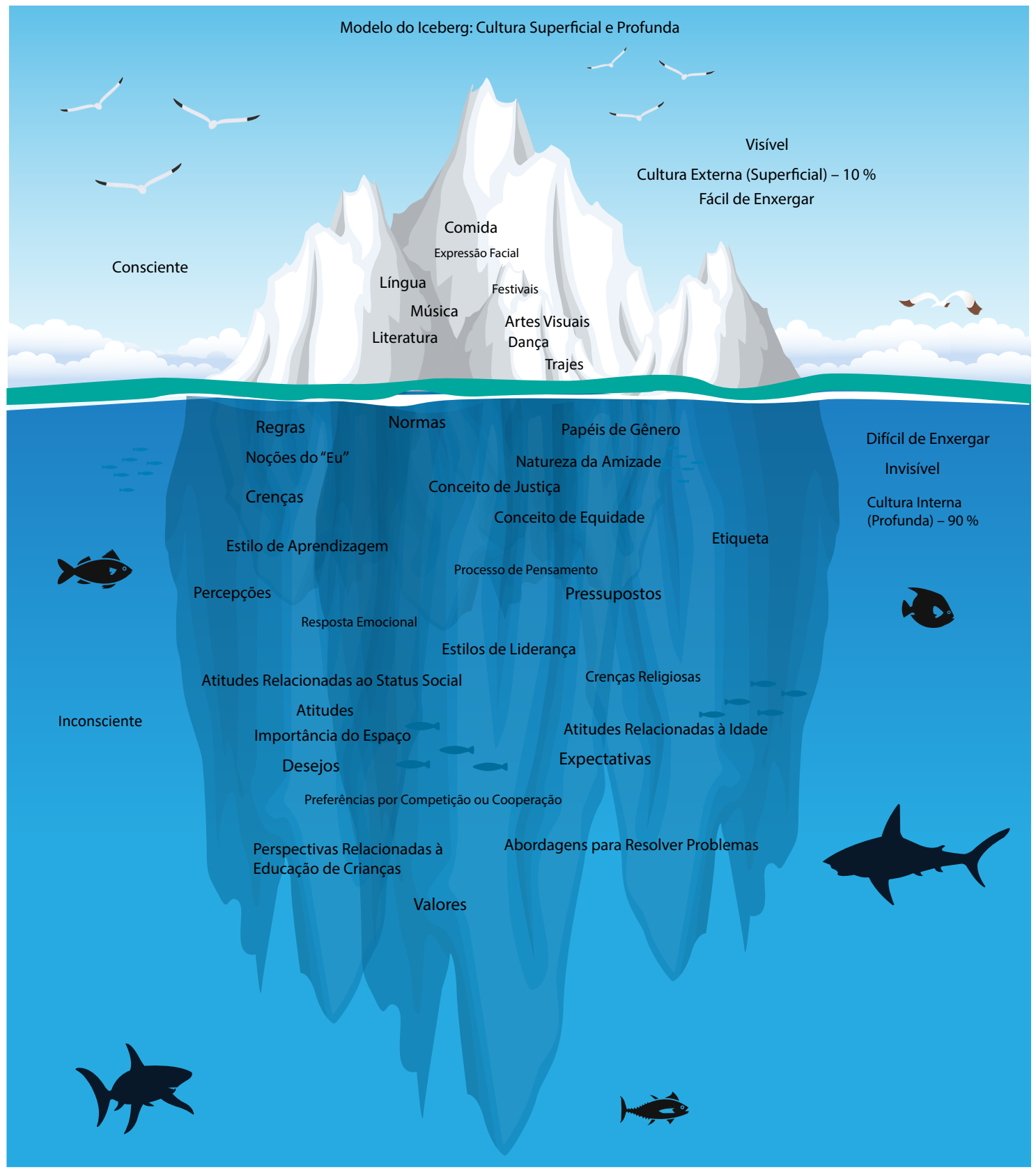

Figura 4. Cultura representada como iceberg - valores visíveis e invisíveis da cultura.

Fonte: What (2016).

Estudos americanos (WHAT..., 2016) estimam que apenas 10\% da cultura seja visível e, portanto, facilmente perceptível, considerando-se que $90 \%$ seja exatamente a cultura profunda: se não compreendermos e atuarmos nos elementos desta última, não conseguiremos influenciar e trabalhar com os fatores da primeira. Isso é ilustrado por meio da Figura 5: a visão de mundo determina crenças e valores, que determinam 
atitudes, que determinam comportamentos, que, por sua vez, determinam manifestações e artefatos da cultura.

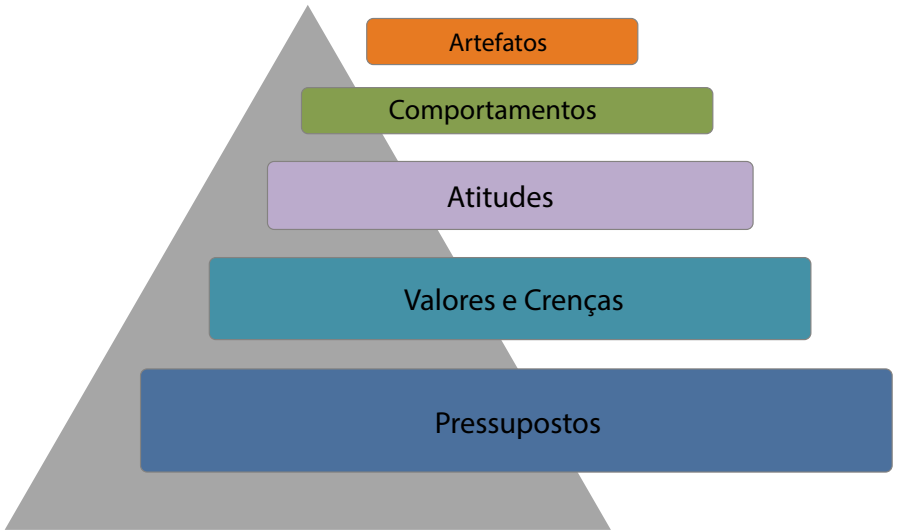

Figura 5. Camadas de elementos que se sobrepõe ao longo do tempo na formação de uma cultura.

Fonte: Links (2013).

Portanto, estrategicamente, precisamos conhecer os elementos da nossa cultura corporativa (além da superfície visível) para traçarmos as ações de branding em sintonia com eles e até mesmo potencializando-os. No entanto, quando ocorrem transformações profundas no mundo, requerendo novos comportamentos e atitudes por parte das organizações, muitas vezes torna-se impossível um alinhamento de elementos da cultura corporativa estabelecida com as novas necessidades. Nessas situações, quando a cultura corporativa é antagônica ou desassociada aos valores e propósitos a serem alcançados pelo branding, é preciso desenvolver um processo de transformação da cultura para se obter o alinhamento estratégico necessário.

\section{Propósito de marca e cultura}

As estratégias de marca são profundamente associadas a propósitos, pois essa é uma das principais formas de se conseguir relevância entre os seus públicos. Entretanto, o propósito depende de dois fatores internos à organização (o que ela ama fazer e o que ela sabe fazer) e um fator externo (o que o mundo precisa), como representado na Figura 6.

\section{PROPósITo}

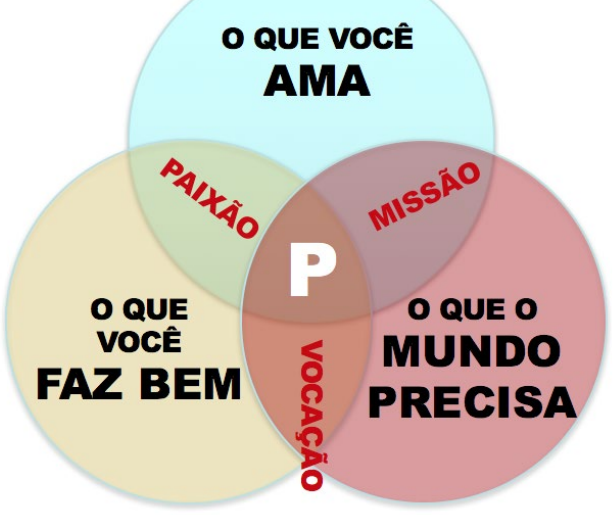

Figura 6. As dimensões do propósito: vocação, razão de ser e bem-estar comum. 
Quando "o que o mundo precisa” muda (Figura 6), isso afeta o propósito da marca (P), pois requer um realinhamento com "o que você faz bem" e "o que você ama fazer". Considerando que o que fazemos depende intrinsecamente da cultura corporativa, podemos dizer que o propósito de uma organização depende da sua cultura para ser alcançado. Por exemplo, as demandas de igualdade de gêneros na sociedade nos últimos anos impactam diretamente "o que o mundo precisa", exercendo uma pressão externa de diversos públicos sobre o propósito das marcas, no sentido de abraçar e atuar nessa direção. Se a cultura corporativa das organizações não consegue se alinhar com esse novo propósito, ocorre um desgaste da imagem da marca com aqueles públicos. Quanto maior o impacto de uma demanda no propósito, maior será a importância de ajuste (ou mudança) na cultura corporativa para incorporar os valores a ele relacionados.

Devido à aceleração no ritmo de mudanças no mundo nas últimas décadas, somadas à hiperconexão e ao crescimento das ações de colaboração global (que favorecem a aproximação de culturas distintas, mas que não necessariamente estão em conexão), temos experimentado um aumento de complexidade no ambiente, marcado com grandes e constantes transformações sociais, que causam uma pressão externa contínua no fator "o que o mundo precisa". Esse cenário requer, consequentemente, mudanças frequentes na cultura corporativa para acompanhar as novas demandas do mercado para garantir a continuidade e sustentabilidade das estratégias de branding. Uma das principais demandas estratégicas, além do branding, que tem requerido transformação das culturas corporativas é a inovação. Uma pesquisa global do Boston Consulting Group (BCG) revela que inovação é prioridade para 75\% das organizações (THE MOST..., 2014). Tal resultado é reflexo da aceleração tecnológica no mundo, que demanda transformação da cultura corporativa para se tornar mais inovadora, como caminho possível para acompanhar as mudanças. Discutiremos a seguir a transformação da cultura corporativa quando necessária.

\section{USANDO OU TRANSFORMANDO ESTRATEGICAMENTE A CULTURA CORPORATIVA}

Para nos servirmos da cultura corporativa em benefício da estratégia de branding, é necessário abraçar, em algum grau, as visões de mundo, os valores e as crenças das pessoas dentro da organização, engajandoas para se comportarem e agirem de forma alinhada e favorecerem os objetivos propostos.

Sabe-se que o esforço para engajar uma pessoa é inversamente proporcional à relevância que essa pessoa atribui à mensagem ou ao estímulo que recebe. Como exemplo, podemos dizer que é muito mais fácil fazer alguém que esteja estudando música clássica comprar um $\mathrm{CD}$ de Chopin do que alguém que só se interessa por rock e heavy metal. Dessa forma, a maneira mais eficiente de se conseguir engajamento é realmente conhecer muito bem o seu público e o que é relevante para ele em cada tempo e lugar, seus valores e aspirações. É essa a tentativa do Google com os links patrocinados: por meio de sistemas inteligentes, oferece ao seu usuário um anúncio com um assunto alinhado com o que ele está buscando ou lendo no momento, portanto, relevante para ele naquele instante. As chances de chamar a atenção e de engajar (com o clique) aumentam bastante devido à relevância.

Assim, a relevância é o caminho natural para o engajamento das pessoas e tem sido a solução utilizada pelo marketing para atrair e manter 
o seu público. No entanto, como fazemos para conseguir engajamento quando a demanda proposta tem baixa ou nenhuma relevância para uma pessoa? Ou até mesmo quando existe rejeição? Essa é a situação de culturas desalinhadas com os objetivos estratégicos da organização e isso é muito mais comum do que se imagina. Por exemplo, como fazer que os funcionários de uma organização passem a utilizar um software específico que é importante para a empresa, mas que eles não se interessem ou acreditem, ou seja, não é relevante para eles? Como fazer que as pessoas adquiram hábitos benéficos para a sustentabilidade ambiental quando elas não se importam com isso, quando não estão interessadas no meio ambiente? Como conseguir que as pessoas descartem lixo eletrônico de forma adequada, quando isso será um trabalho adicional para elas? Como conseguir mudar a cultura de uma empresa, modificando hábitos dos colaboradores quando eles não estão interessados na mudança, ou pior, não acreditam nela? Em suma, como conseguir engajamento das pessoas em situações que não são consideradas relevantes para elas, mas que são muito relevantes ou importantes para uma determinada instituição, entidade ou sociedade? Certamente é bem mais difícil do que engajar pessoas por meio dos valores que são relevantes para elas.

Em engenharia, utilizamos a metodologia dos “3 Es" para solucionar problemas de tráfego. Os "Es" se referem a education, engineering e enforcement - ou, em português, educação, engenharia e execução (no sentido de "fazer cumprir"). Em certa medida, este modelo pode ser aplicado para qualquer ação de engajamento em que se deseja que o público atue de forma contrária aos seus interesses imediatos, tendo-se como meta um objetivo maior, coletivo. Dessa forma, adaptaremos a metodologia para gerar engajamento social e transformação de cultura como: educação, estrutura e estímulo. Vamos aos “3 Es”:

Primeiro E - a educação é a base dos relacionamentos sociais, que cria, ao longo do tempo, percepções e comportamentos. Considerando-se que cultura é aprendizado, podemos dizer que a educação transforma a cultura. Existem diversas teorias sobre como educar que vão além do escopo deste texto. No entanto, o que importa salientar aqui é que a educação tem o poder de engajar as pessoas com o bem comum, relegando o interesse pessoal a um segundo plano. A educação, quando incorporada numa população, regula a própria sociedade. Vamos usar um exemplo bem simples para ilustrar isso. Em comunidades onde a educação valoriza a limpeza como valor essencial, os seus indivíduos fiscalizam e recriminam quem joga lixo no chão, inibindo tal comportamento. Quando necessitamos uma mudança de cultura, o primeiro passo é educar. Não podemos esperar que as pessoas saibam automaticamente aquilo que queremos se não as informamos. Um exemplo do uso da educação para os valores da cultura corporativa é a Figura 7, que mostra a declaração de cultura da Sensedia.

Segundo E - a estrutura, ou mais genericamente, processos e tecnologia, considerando-se que, muitas vezes, para se conseguir que as pessoas adquiram educação para se engajarem, são necessárias estruturas que as auxiliem. Voltemos ao nosso exemplo anterior, sobre jogar lixo no chão. Mesmo que a população seja educada e não queira jogar lixo no chão, fica muito difícil exercitar a educação se não houver lixeiras disponíveis para que elas possam descartar adequadamente, o que fará que, eventualmente, algumas pessoas passem a jogar o lixo em qualquer lugar, inclusive, no chão. Um outro exemplo, muito comum atualmente, é a necessidade de transformação da cultura corporativa para abraçar a diversidade e igualdade em todas as dimensões. Para tanto, é necessário 
que a governança corporativa estabeleça regras e estruturas para que a igualdade e diversidade aconteçam, caso contrário, torna-se improvável que o processo se estabeleça de forma sistêmica na organização. Assim, a função do segundo E é viabilizar os processos para que o engajamento aconteça e a governança corporativa exerce um papel fundamental nesse sentido.

\section{Manifesto da Cultura Sensedia}

\section{Agilidade ao invés de Burocracia}

Transparência ao invés de Cochichos

Pedir desculpas ao invés de Pedir permissão

Cliente ao invés de Nosso umbigo

Ética ao invés de Jeitinhos

Inovação ao invés de Mesmice

Nome ao invés do Login

Figura 7. Manifesto da cultura corporativa da Sensedia

Fonte: Bacili (2015).

Terceiro E - o estímulo, ou “incentivar o fazer”, sendo que, em alguns casos, mesmo existindo educação e estrutura, eventualmente elas podem não ser suficientes para motivar o engajamento devido a resistências enraizadas na cultura e em cada indivíduo. Se as pessoas continuam a jogar lixo no chão - partindo da ideia do nosso exemplo anterior - mesmo depois de um processo de educação e existindo lixeiras disponíveis, uma das formas de engajá-las seria por meio da implementação de alguma lei que as incentivasse a cumprir o comportamento desejado até que este se incorpore sistemicamente na cultura - a partir disso, passaria a não ser mais necessário nenhum tipo de lei, pois a própria sociedade faria uma autofiscalização. Outra forma mais interessante e não punitiva seria premiar as pessoas que jogam o lixo nos locais apropriados, incentivando o comportamento desejado até se incorporar sistemicamente na cultura, de forma que a premiação se torne desnecessária.

Assim, existem dois tipos principais de estímulos: os positivos, que envolvem algum tipo de premiação a fim de estimular o comportamento desejado, e os negativos, que se referem a algum tipo de "punição" quando o comportamento não é adotado. Demandas novas, que não existam anteriormente na cultura, justamente por serem novidades - como uso de softwares de CRM, sistemas de gestão do conhecimento, redes sociais digitais, descarte de lixo eletrônico etc. -, normalmente requerem estímulos para causar engajamento. Um exemplo que mostra isso foi o processo de engajamento da população para o uso do cinto de segurança em São Paulo na década de 1990. Apesar das inúmeras campanhas de comunicação informando os riscos e perigos de não se usar o cinto de segurança, e mesmo os veículos estando equipados com cintos em todos os assentos, as pessoas não adotavam o uso do cinto.

Portanto, apesar de se ter os "Es" de educação e estrutura, era necessário um estímulo para engajar. A solução foi a criação da lei de obrigatoriedade de uso de cintos de segurança, que aplicava multa aos 
motoristas que a descumprissem. Num primeiro momento, as pessoas usavam os cintos de segurança para não serem multadas (estímulo negativo), mas ao longo do tempo a maioria da população de São Paulo incorporou o uso do cinto na cultura e hoje a multa não é o motivador principal do seu uso. A educação é, sem dúvida, o principal fator e a base para um engajamento ideal, enquanto os outros dois fatores, estrutura e estímulo, visam dar suporte à educação que engaja. Assim, os 3 "Es" trabalham juntos em diferentes graus para se conseguir engajamento em processos que não têm a atenção e o interesse do público-alvo. Logicamente, eles devem ser ajustados caso a caso, conforme o objetivo de engajamento e o contexto.

\section{CONSIDERAÇÕES FINAIS}

Conforme o mundo se torna mais complexo e acelerado devido à penetração tecnológica na sociedade, novas demandas impactam as organizações requerendo alinhamentos de propósitos e estratégias de branding para continuarem relevantes para seus públicos. Por outro lado, para ter sucesso é essencial que o branding esteja em ressonância com a cultura corporativa e seus valores, pois a cultura funciona como um filtro que determina, favorece ou limita qualquer estratégia mercadológica ou comunicacional.

Dessa forma, para engajar as pessoas da organização, o branding pode se utilizar e apropriar da cultura corporativa para favorecer suas possibilidades de construção de vínculos com sentido. No entanto, quando as demandas de mercado não encontram alinhamento possível com a cultura corporativa existente, é necessário um processo de transformação de elementos dessa cultura interna, que pode ser conseguido por meio de metodologias de engajamento, como os “3Es” do engajamento aqui proposto, adaptado das metodologias de segurança em engenharia de tráfego (GABRIEL, 2012).

Em função do cenário de mercado que se delineia, cada vez mais complexo e acelerado, esses processos de alinhamento de fluxos estratégicos de branding com a cultura corporativa tendem a ser cada vez mais frequentes como caminho rentável para garantir a sustentabilidade de resultados para as marcas e organizações.

\section{REFERÊNCIAS}

BACILI, K. Propósito e cultura corporativa. 2015. Disponível em: <https://goo.gl/k6ckYX>. Acesso em: 9 ago. 2016.

CANCLINI, N. G. Culturas híbridas: estratégias para entrar y salir de la modernidade. Barcelona: Grijalbo, 1990.

CULTURE. In: WIKIPEDIA, a enciclopédia livre. Flórida: Wikimedia Foundation, 2017. Disponivel em: <https://goo.gl/tRVNDR>. Acesso em: 9 ago. 2016.

COLORS in culture. Information Is Beautiful, [S.I.], [9 abr. 2017?]. Disponivel em: <https:// goo.gl/T43dEh>. Acesso em: 9 ago. 2016.

DAVENPORT, T. H.; BECK, J. C. Economia da atenção. São Paulo: Elsevier, 2001.

DIA dos Namorados O Boticário. O'30". O Boticário, YouTube, 2015. Disponível em: <https://goo.gl/RHQXEM>. Acesso em: 5 jul. 2015.

GABRIEL, M. Os 3Es do Engajamento. Martha Gabriel PhD, São Paulo, 6 jan. 2012. Disponível em: <https://goo.gl/P5pKhH>. Acesso em: 2 maio 2011. 
LINKS between Sattler's attack on Gillard, AFL 'ape' ramark, Menugate and 3\% asian on boards. Stepping Up Australia, Sydney, 16 jun. 2013. Disponível em: <https://goo.gl/XpXSwg>. Acessado em: 5 ago. 2016

MAYHEW, M. How culture influences Health. Caring for Kids New Canada, Ottawa, jan. 2016. Disponível em <https://goo.gl/TtHcQZ>. Acesso em: 9 ago. 2016.

PEIRCE, C. S. Semiótica. São Paulo: Perspectiva, 1977.

PEREZ, C. Signos da marca: expressividade e sensorialidade. 2. ed. São Paulo: Cengage Learning, 2016.

SANTAELLA, L. Percepção: fenomenologia, ecologia e semiótica. São Paulo: Cengage Learning, 2011.

Paulus, 2003.

Culturas e artes do pós-humano: da cultura das mídias à cibercultura. São Paulo:

SCHEIN, E. H. Cultura organizacional e liderança. São Paulo: Atlas, 2009.

THE MOST innovative companies 2014: breaking through is hard to do. BCG Perspectives, Boston, [2014?]. Disponivel em: <https://goo.gl/up8exK>. Acesso em: 15 dez. 2014.

TORBEN, R. Corporate culture is driving the strategy or undermining it. Ameliorate, Hamburg, 3 dez. 2013. Disponível em <https://goo.gl/V3VGg4>. Acesso em: 9 ago. 2016.

YOUNG, P. Stepping up: lead culture change for diversity and growth in the Asian century. Sydney: Growthcurv, 2013.

WHAT is culture and how is it defined? Cultural Conflict, [S.I.], 9 nov. 2013. Disponível em: <https://goo.gl/Krgu1k>. Acesso em: 9 ago. 2016. 